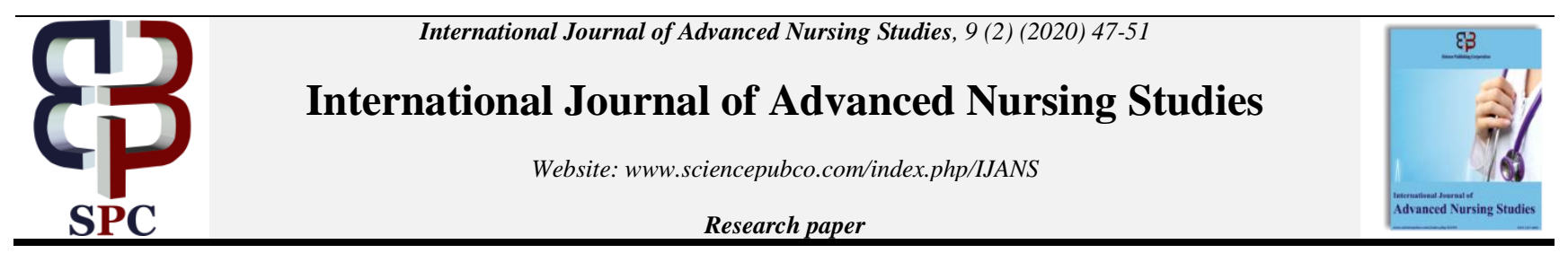

\title{
Psychosocial distress among patients with cancer at a county referral hospital in Kenya
}

\author{
Francis Justin Kinoti ${ }^{1}{ }^{*}$, Sherry Oluchina ${ }^{2}$, Bernard Wambua Mbithi ${ }^{3}$ \\ ${ }^{1}$ Master of science in nursing student, Jomo Kenyatta University of Agriculture and Technology, Kenya \\ ${ }^{2}$ Senior lecturer, School of Nursing, Jomo Kenyatta University of Agriculture and Technology \\ ${ }^{3}$ Lecturer, School of Nursing, Jomo Kenyatta University of Agriculture and Technology \\ *Corresponding author E-mail: fankuzat2014@gmail.com
}

\begin{abstract}
Introduction: Cancer diagnosis and treatment are emotionally draining to patients and their caregivers. For a long time, treatment for cancer has been associated with pain, suffering and death. These negative consequences of cancer create psychosocial effects such as anxiety and fear. Therefore, there is need to recognize and accurately identify this psychosocial distress problems on patients with cancer by healthcare providers to figure out interventions for these psychosocial issues.

Objective: To assess the psychosocial distress among patients with cancer attending the Machakos county referral hospital palliative care unit.

Subjects and Methods: Data were collected through descriptive cross-sectional design where a total of 97 patients were interviewed and filled the questionnaires and the National Cancer Center Network distress thermometer and problem list. The data was analyzed using the Statistical Package for Social Sciences (SPSS) for windows version 24. Descriptive statistics such as the means, standard deviation and frequencies were generated and Pearson Chi square test of association computed to determine the associations between the independent and the dependent variables. The confidence interval was set at $95 \%(\mathrm{p} \leq 0.05)$.

Results: The study findings revealed that $72.2 \%$ of the respondents were distressed. Majority $(83.3 \%)$ of the respondents reported being in pain, $64.9 \%$ of them cited problems with decision making about treatment, while $59.8 \%$ of the respondents said that they were experiencing fatigue. Other issues cited by the respondents included financial constraints and facing difficulties while eating. The study results also showed that there was statistically significant association between having psychosocial distress and gender $(\mathrm{P}=0.015)$ and cancer treatment $(\mathrm{P}=0.015)$.

Conclusion: There is a very high prevalence of psychosocial distress among patients with cancer with the leading psychosocial distress problem being pain.
\end{abstract}

Keywords: Cancer Care; Pain; Psycho-Oncology; Psychosocial Distress Problems; Psychosocial Distress Screening.

\section{Introduction}

The diagnosis and treatment of cancer are emotionally draining and are associated with pain, suffering and death ((Powe \& Finne, 2003), which lead to psychosocial distress symptoms such as anxiety, fear and depression. The National Comprehensive Cancer Network (NCCN) report (2011) defined distress as a multifactorial unpleasant emotional experience of a psychological (cognitive, behavioral, emotional) social, and/or spiritual nature that may interfere with the ability of a person to cope effectively with cancer, its physical symptoms and its treatment. This distress can be placed on a continuum, from common normal feelings of vulnerability, sadness, and fear to problems that can become disabling, such as depression, anxiety, panic, social isolation, and existential and spiritual crisis.

Psychosocial distress affects all cancer patients and is a significant health problem that must be addressed at every stage of cancer care trajectory (Weeratunga, Senadheera, \& Ekanayake, 2016). A study by Zabora et al. (2001) concluded that the overall prevalence of psychological distress among patients with cancer was $35.1 \%$. This prevalence varied by cancer type with people diagnosed with lung experiencing the most rated of distress (43.4\%), followed by those with brain (42.7\%), gynecological (29.6\%), prostate (30.5\%), and colon (31.6\%) cancer. In Qatar, Hassan et al, (2018) indicated an overall prevalence of 62\% while a Moroccan based study revealed that psychosocial distress among patients with breast cancer was $46.6 \%$ (Berhili, et al., 2017).

In 2009, the International Psycho-Oncology Society (IPOS) unanimously endorsed the concept of distress as the sixth vital sign in cancer settings alongside temperature, respiration, heart rate, blood pressure and pain. The society further determined that distress is a fundamental factor in patient wellbeing and therefore same should be routinely assessed during patient care. Since then, the idea has been adopted and endorsed by the World Health Organization (WHO), ministries of health, NCCN and United Kingdom based charities such as Breast Cancer Care, the British Psychosocial Oncology Society and Macmillan Cancer Support among others (Swash, 2015).

In Kenya, cancer ranks third as a cause of death after infectious and cardiovascular diseases (Ministry of Health, Kenya, 2017). It causes about $7 \%$ of the total national mortality every year. The Ministry of Health estimates that the annual incidence of cancer is about 28,000 new cases with an annual mortality of 22,000 cases. According to the Kenya national cancer registry (2014-2016) report, the top three 
cancer diseases in women are breast, cervical and oesophagus while in men they are oesophagus, prostate and Kaposi's sarcoma are the most common (MOH, 2017).

The Kenya national palliative care guidelines (2013) recommend that patients on palliation and their families/caregivers should be informed of common psychosocial problems facing palliative patients including anxiety, depression, advanced care plans, care for children, finances, will, community support, and family relationships. Each of these psychosocial concerns by patients with cancer should be assessed comprehensively by the health care provider and intervene, possibly leading to better compliance with overall prescribed treatment, and possibly yielding a better prognosis. Therefore, the main purpose of this study was to determine the prevalence of psychosocial distress and associated factors among patients with cancer attending the Machakos county referral hospital palliative care unit.

\section{Subjects and methods}

\subsection{Study setting, design and population}

The study was carried out at the Machakos county referral hospital palliative care unit (in Kenya) whereby cross-sectional study design was used to collect data from 97 patients with cancer.

\subsection{Sample selection and sample size}

The researcher used census technique, whereby all the patients with cancer above the age of 18 years with histologically confirmed malignancy and consented for the study were recruited. Patients who were seriously ill, those who were suffering from psychiatric and mental disorders, diabetes and hypertension and/or those who were coming for a revisit during the data collection period were excluded. A total of 97 patients with cancer participated in the study.

\subsection{Data collection}

Data were collected using questionnaires and NCCN distress thermometer and problem list over a period of one month. The questionnaire captured socio-demographic data of the respondents and other factors associated with psychosocial distress among patients with cancer which was developed following an extensive literature review.

National Cancer Center Network distress thermometer and problem list was used to gather data on self-reported level of psychosocial distress and the accompanying problems. Distress thermometer is a self-report tool that has been validated in numerous adult cancer populations in many countries and is used to assess psychosocial distress from patients with cancer (Donovan, Grassi, McGinty, \& Jacobsen, 2014). It consists of a visual analogue to which the patient responds by indicating level of distress from $0=$ no distress to $10=$ extreme distress over a period of one prior week. The level of distress was classified into three categories: mild distress $=$ a rating by patient of less than 4 , moderate distress $=$ rating of $4-7$, and severe distress $=$ a rating greater than 7 (NCCN, 2010). According to the NCCN guidelines, scores of four or higher suggest a level of distress that has clinical significance indicating a state of distress by the patient while a patient scoring less than four is reported as not distressed. Administration of the 39- item Problem List, which was on the same page as the distress thermometer, involved asking patients to identify their problems causing psychosocial distress on the list in five different categories; practical, family, emotional, spiritual/religious, and physical.

\subsection{Pre-test of the questionnaire}

Pretest data were gathered using the semi structured questionnaires at Machakos palliative care unit. The questionnaire was administered to $10 \%$ of the estimated study participants a week prior to commencement of the actual study. The patients who participated in the pre-test were not recruited in the main study.

\subsection{Data analysis and presentation of findings}

The data gathered using the questionnaires and screening tools were cleaned and checked for completeness then entered into a computer database and analyzed using SPSS for windows version 24. Chi square test of association was computed to determine statistical association between the independent and the dependent variables with the confidence interval set at $95 \%$. Presentation of descriptive data were done using charts and tables.

\subsection{Ethical consideration}

An introduction letter was obtained from Jomo Kenyatta University of Agriculture and Technology- School of Nursing after which the proposal was presented to The Nairobi Hospital Bioethics and Research Committee for ethical clearance and approval (Ref: TNH/ADMIN/CEO/13/08/19). Clearance to collect data was also obtained from the National Council of Science and Technology (License No.: NACOSTI/P/19/1024), Machakos County Referral Hospital management team and the person in charge of Machakos palliative care clinic unit. Further, a confirmation of the consent by the client was obtained by signing an informed consent form.

\section{Results}

\subsection{Prevalence of psychosocial distress among patients with cancer}

Using a self-scoring NNCN distress thermometer with scores from 0-3 (indicating mild distress), 4-7 (indicating moderate distress), 8-10 (indicating severe distress), 41.2\% (40) of the respondents reported severe distress, 30.9\% (30) of the participants experienced moderate while $27.8 \%$ (27) of them were experienced mild distress (Figure 1). 


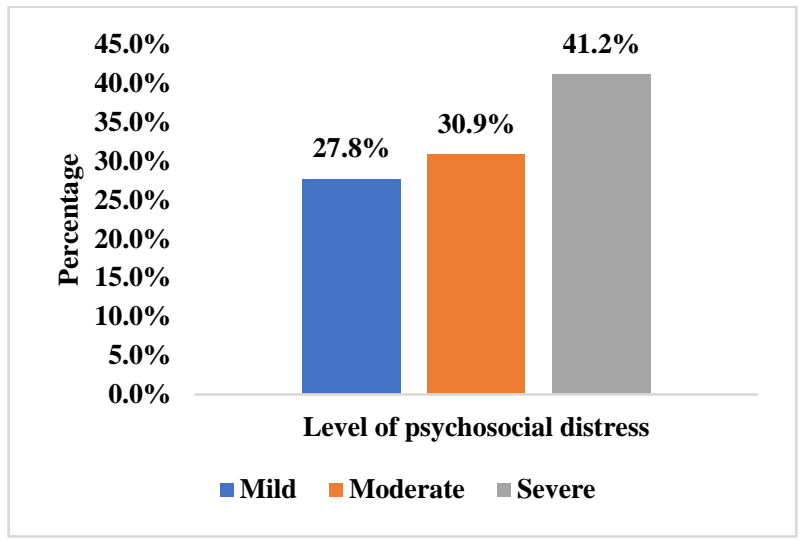

Fig. 1: Level of Psychosocial Distress among the Respondents.

The respondents were further categorized into two groups, with those scoring 0-3 in the "no distress" and those scoring 4-10 in the "distressed" groups. A significant majority $(72.2 \%, 70)$ of study participants scored 4 and above indicating that they were distressed (Figure 2.)

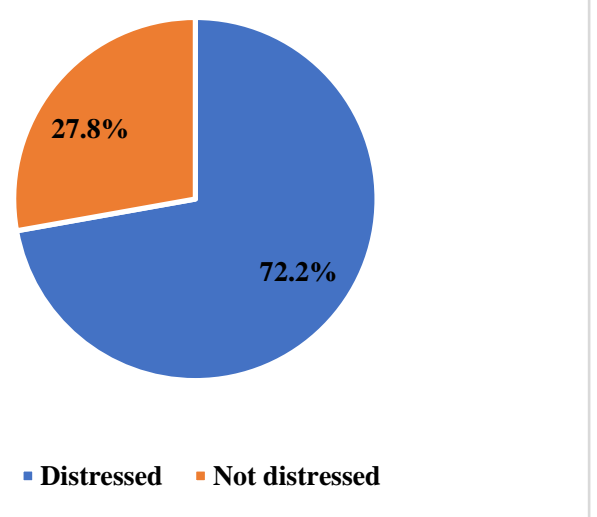

Fig. 2: Psychosocial Distress Status among the Respondents.

\subsection{Psychosocial distress problems among the cancer patients}

In regard to psychosocial distress problems presenting among patients with cancer, the most prevalent problems reported were pain (83.3\%), problems making treatment decisions (64.9\%), fatigue (59.8\%), insurance/financial constrains (57.7\%), worry (50.5\%) and eating (50.5\%) as shown in table 1.

Table 1: Respondents Answers to the Questions on the Problem List

\begin{tabular}{|c|c|}
\hline Problem list categories & Responses (Yes) (\%) \\
\hline \multicolumn{2}{|l|}{ Practical problems } \\
\hline Child care & $32(33.0)$ \\
\hline Housing & $5(5.2)$ \\
\hline Insurance/financial & $56(57.7)$ \\
\hline Transportation & $43(44.3)$ \\
\hline Work/school & $20(20.6)$ \\
\hline Treatment decisions & $63(64.9)$ \\
\hline \multicolumn{2}{|l|}{ Family problems } \\
\hline Dealing with children & $23(23.7)$ \\
\hline Dealing with partner & $16(16.5)$ \\
\hline Ability to have children & $3(3.1)$ \\
\hline Family health issues & $21(21.6)$ \\
\hline \multicolumn{2}{|l|}{ Emotional problems } \\
\hline Depression & $32(33.0)$ \\
\hline Fears & $39(40.2)$ \\
\hline Nervousness & $22(22.7)$ \\
\hline Sadness & $24(24.7)$ \\
\hline Worry & $49(50.5)$ \\
\hline Loss of interest in usual activities & $32(33.0)$ \\
\hline \multicolumn{2}{|l|}{ Physical problems } \\
\hline Appearance & $31(32.3)$ \\
\hline Bathing/dressing & $15(15.5)$ \\
\hline Breathing & $5(5.2)$ \\
\hline Changes in urination & $12(12.4)$ \\
\hline Constipation & $27(27.8)$ \\
\hline Diarrhea & $4(4.1)$ \\
\hline Eating & $49(50.5)$ \\
\hline
\end{tabular}




$\begin{array}{ll}\text { Fatigue } & 58(59.8) \\ \text { Feeling swollen } & 16(16.7) \\ \text { Fevers } & 16(16.5) \\ \text { Getting around } & 28(28.9) \\ \text { Indigestion } & 37(38.1) \\ \text { Memory/concentration } & 10(10.3) \\ \text { Mouth sores } & 9(9.3) \\ \text { Nausea } & 19(19.6) \\ \text { Nose dry/congested } & 6(6.2) \\ \text { Pain } & 80(83.3) \\ \text { Sexual } & 35(36.1) \\ \text { Skin dry/itchy } & 9(9.3) \\ \text { Sleep } & 42(43.3) \\ \text { Substance abuse } & 3(3.1) \\ \text { Tingling in hand/feet } & 9(9.3) \\ \text { Spiritual/religious concerns } & 69(71.1) \\ \end{array}$

\subsection{Socio-demographic factors associated with self-reported psychosocial distress status among the cancer patients}

The demographic information of the study participants is presented in Table 2. Out of the 97 participants, 36.1\% (35) were above the age of 58 years, with majority $(70.1 \%, n=68)$ of the participants being females while $69.1 \%$ (67) of them were married. In terms of the level of education, $43.3 \%$ (42) of the study participants had attained primary education. Among the study participants, 56.7\% (55) of them had been diagnosed with cancer in the past one year with about $50.5 \%$ (49) of them receiving cancer treatment.

Pearson Chi-Square test of association indicated a significant relationship between socio-demographic factors and psychosocial distress among patients with cancer. Among the factors in the analysis, gender $(\mathrm{P}=0.015, \chi 2=5.946)$, period since diagnosis $(\chi 2=11.08, \mathrm{p}=0.026)$ and cancer treatment $(\chi 2=5.900, p=0.015)$ had statistically significant association with psychosocial distress.

Table 2: Socio-Demographic Factors Associated with Psychosocial Distress among Patients with Cancer

\begin{tabular}{|c|c|c|c|c|c|}
\hline & $\mathrm{n}(\%)$ & Not distressed & Distressed & $\chi^{2}$ & p-value \\
\hline \multicolumn{6}{|l|}{ Age in years } \\
\hline $18-27$ & $6(6.2)$ & 0 & 6 & \multirow{5}{*}{5.200} & \multirow{5}{*}{0.267} \\
\hline $28-37$ & $9(9.3)$ & 1 & 8 & & \\
\hline $38-47$ & $20(20.6)$ & 5 & 15 & & \\
\hline $48-57$ & $27(27.8)$ & 8 & 19 & & \\
\hline 58 and above & $35(36.1)$ & 13 & 22 & & \\
\hline \multicolumn{6}{|l|}{ Gender } \\
\hline Male & $29(29.9)$ & 13 & 16 & \multirow{3}{*}{5.946} & \multirow[b]{2}{*}{0.015} \\
\hline Female & $68(70.1)$ & 14 & 54 & & \\
\hline \multicolumn{5}{|l|}{ Marital status } & \\
\hline Single & $6(6.2)$ & 0 & 6 & \multirow{4}{*}{5.153} & \multirow{4}{*}{0.161} \\
\hline Married & $67(69.1)$ & 20 & 47 & & \\
\hline Divorced/separated & 11(11.3) & 5 & 6 & & \\
\hline Widowed & $13(13.4)$ & 2 & 11 & & \\
\hline \multicolumn{6}{|l|}{ Level of education } \\
\hline Never gone to school & $16(16.5)$ & 4 & 12 & \multirow{6}{*}{1.521} & \multirow{6}{*}{0.823} \\
\hline Never gone to school/can read \& write & $5(5.2)$ & 1 & 4 & & \\
\hline Primary & $42(43.3)$ & 10 & 32 & & \\
\hline Secondary & $25(25.8)$ & 9 & 16 & & \\
\hline Post-secondary & $9(9.3)$ & 3 & 6 & & \\
\hline Unemployed & $31(32.0)$ & 5 & 26 & & \\
\hline \multicolumn{6}{|l|}{ Period since diagnosis } \\
\hline Less than 1 year & $55(56.7)$ & 11 & 44 & \multirow{4}{*}{11.08} & \multirow{4}{*}{0.026} \\
\hline $1-3$ years & $22(22.7)$ & 6 & 16 & & \\
\hline $3-5$ years & $7(7.2)$ & 2 & 5 & & \\
\hline More than 5 year & $13(13.4)$ & 8 & 5 & & \\
\hline \multicolumn{6}{|l|}{ Whether received cancer treatment } \\
\hline Yes & $49(50.5)$ & 19 & 30 & \multirow[t]{2}{*}{5.900} & \multirow[t]{2}{*}{0.015} \\
\hline No & $48(49.5)$ & 8 & 40 & & \\
\hline
\end{tabular}

\section{Discussion}

In this study the NCCN distress thermometer and problem list, a self-report tool for assessing psychosocial distress in patients with cancer was used to assess distress among patients with cancer at Machakos palliative care unit. Majority of the study participants (72.2\%) were distressed with $43.2 \%$ indicating severe levels of psychosocial distress. The findings revealed substantial distress among patients with cancer than reported internationally. For example, in Qatar, Hassan et al. (2018) reported an overall distress prevalence of 62\% which was slightly lower than the findings in the current study. Likewise, in Sri Lanka Weeratunga et al. (2016) reported that 65\% of the participants in their study had severe levels of distress.

In regard to psychosocial distress problems presenting among patients with cancer, the most prevalent problems reported were pain (83.3\%), problems making treatment decisions (64.9\%), fatigue (59.8\%), insurance/financial constrains (57.7\%), worry (50.5\%) and eating (50.5\%). These findings are in agreement with findings by Taghizadeh et al. (2018) in Iran that fatigue and pain were among the most frequently presenting psychosocial problems among patients with cancer. Taghizadeh and colleagues recommended a supportive and palliative care model to reduce pain and enhance the functional status of patients with cancer.

Similarly, Loscalzo and Clark (2007) found that fatigue (41.9\%), sleep (32.5\%), finances (31.1\%), pain (29.4\%) and fear and worry (28.2\%) were the top five problems reported by patients with cancer. The finding that pain is the most prevalent distress problem is consistent with 
a study by Doyle et al. (2017) in India who found that $88 \%$ of the patients with cancer in their study reported pain and felt that they received inadequate pain management care.

The majority of the patients with cancer (64.9\%) also reported to having a problem in making treatment decisions. The limited number of healthcare professionals in oncology clinics in Kenya and other developing countries means that these health care providers have little time to educate patients about their diagnosis and available treatment options. This shortcoming, coupled with low literacy levels as established in this study, could explain the problems expressed by patients in making treatment decisions. This finding would be comparable to what Stacey (2010) found in Ottawa, Ontario Canada that patients who were not satisfied with information offered after diagnosis by the oncology team, felt that more discussion was needed to answer their question so as for them to be an active part of decision making about their care.

In the present study it was clear that gender $(\mathrm{P}=0.015)$ was associated with psychosocial distress among patients with cancer. Female patients were more likely to be distressed than their male counterparts. This finding was consistent with the results in a study by Taghizadeh et al. (2018) indicating greater distress among female patients with cancer in Iran. However, in Malaysia, Priscilla, et al. (2011) found that female patients with cancer actually reported much better quality of life and lower distress than their male counterparts.

Hassan et al. (2018) found that among patients in the initial phase of the disease (56\%) and those undergoing treatment (54\%) had the highest psychosocial distress level. The findings by Hassan and colleagues were consistent with the findings in the present study that there were statistically significant associations between period since cancer diagnosis $(\mathrm{p}=0.026)$, cancer treatment $(\mathrm{p}=0.015)$ and $\mathrm{psychosocial}$ distress among patients with cancer.

\section{Conclusion}

The results of the current study concluded that there was a higher prevalence of psychosocial distress among patients with cancer at Machakos palliative care unit than it is reported internationally. The findings also revealed that pain, problems in making treatment decisions, fatigue, insurance/financial constraints, worry and eating problems are the seven most common reported psychosocial distress problems among patients with cancer.

\section{Recommendations}

Based on the findings of this study, the following suggestions are recommended:

1) All patients with cancer should be comprehensively screened for psychosocial distress at enrollment for the palliative care services and at prescribed intervals. Patients with moderate to severe levels of distress should be referred for intervention by the appropriate care providers, such as the clinical psychologists, psychiatrist, chaplain or a social worker.

2) Moving forward, a longitudinal study is needed to assess psychosocial distress among patients with cancer in all palliative clinics and cancer treatment centers in Kenya so as to make firm conclusions about the psychosocial needs of this patient population at various stages of cancer care trajectory.

\section{References}

[1] Berhili, S., Kadiri, S., Amal , B., Abdallah , A., Elamin , M., Etienne, O., Benjaafar, N. (2017). Associated factors with psychological distress in Moroccan breast cancer patients: A cross-sectional study. The Breast, 26-33. https://doi.org/10.1016/j.breast.2016.10.015.

[2] Donovan, K. A., Grassi, L., McGinty, H. L., \& Jacobsen, P. B. (2014). Validation of the distress thermometer worldwide: state of the science. Psychooncology Journal, 23(3), 241-250. https://doi.org/10.1002/pon.3430.

[3] Doyle, K. E., El Nakib, S. K., Rajagopal, M. R., Babu, S., Joshi, G., Kumarasamy, V., Gayatri , P. (2017). Predictors and Prevalence of Pain and Its Management in Four Regional Cancer Hospitals in India. Journal of Global Oncology. doi:102.166.65.156.

[4] Hassan, A. A., Eziada, S. J., Bashir, A., Gameil, A., Elmalik, H., \& Ayman, A. (2018). Psychosocial distress among cancer patients: A single institution experience at the state of Qatar. Clinical Oncology Journal. https://doi.org/10.1200/JCO.2018.36.15 suppl.e22163.

[5] Loscalzo, M. J., \& Clark, K. L. (2007). Problem-Related Distress in Cancer Patients Drives Requests for Help: A Prospective Study. Oncology Journal.

[6] Ministry of Health, Kenya. (2013). National Guidelines for Cancer Management, Kenya. Nairobi.

[7] Ministry of Health, Kenya. (2017). National Cancer Control Strategy 2017 - 2022.

[8] National Comprehensive Cancer Network (NCCN). (2011). NCCN Clinical Practice Guidelines in Oncology: Distress Management. NCCN Clinical Practice Guidelines in Oncology: Distress Management.

[9] Powe, B. D., \& Finne, R. (2003). Cancer fatalism: the State of the Science. Cancer Nurses Journal, 454- 465. https://doi.org/10.1097/00002820$200312000-00005$.

[10] Priscilla, D., Hamidin, A., Azhar, M. Z., Noorjan, K., Salmiah1, S., \& Bahariah, K. (2011). The Socio-Demographic and Clinical Factors Associated with Quality of Life among Patients with Haematological Cancer in a Large Government Hospital in Malaysia. Kuala Lumpur, Malaysia.

[11] Stacey, D., Paquet, L., \& Samant, R. (2010). Exploring cancer treatment decision-making by patients: a descriptive study. Current Oncology journal, 17(4). https://doi.org/10.3747/co.v17i4.527.

[12] Taghizadeh, A., Pourali, L., Vaziri, Z., Saedi, H. R., Behdani, F., \& Amel, R. (2018). Psychological Distress in Cancer Patients. Middle East Journal of Cancer, 143-149.

[13] Weeratunga, E. B., Senadheera, C., \& Ekanayake, U. (2016). Psychological distress in cancer patients in Southern province of Sri Lanka. Galle, Southern province, Sri Lanka. https://doi.org/10.4038/gmj.v21i2.7951.

[14] Zabora, J., BrintzenhofeSzoc , K., Curbow , B., Hooker, C., \& Piantadosi , S. (2001). The prevalence of psychological distress. Psycho-Oncology, 10. https://doi.org/10.1002/1099-1611(200101/02)10:1<19::AID-PON501>3.0.CO;2-6. 